\title{
Kant: Constitutivism as Capacities-First Philosophy
}

Karl Schafer

$1 / 15 / 19$

Over the last two decades, Kant's name has become closely associated with the "constitutivist" program within metaethics. ${ }^{1}$ But is Kant best read as pursuing a constitutivist approach to metanormative questions? And if so, in what sense? 2

In this essay, I'll argue that we can best answer these questions by considering them in the context of a broader issue - namely, how Kant understands the proper methodology for philosophy in general. The result of this investigation will be that, while Kant can indeed be read as a sort of constitutivist, his constitutivism is ultimately just one instance of a much more general approach to philosophy - which treats as fundamental our basic, self-conscious rational capacities. Thus, to truly understand why and how Kant is a constitutivist, we need to consider this question within the context of his more fundamental commitment to "capacities-first philosophy".

\section{Contemporary Constitutivism}

In a moment, I'll explore these claims in more detail. But before doing so, it will be useful to begin with a brief discussion of "constitutivism" as this term is used today. In what follows, I'll use "constitutivism" to refer to the broad family of meta-normative views that endorse some version of the following:

Core Constitutivist Claim: The fundamental norms that apply to $\mathrm{X}$ are explained by the nature of $X$.

Crucially this definition of constitutivism is silent about two issues. First, it says very little about the sort of philosophical work this mode of "constitutivist explanation" is meant to accomplish. This is worth stressing here because "constitutivism" is often defined so that very dramatic claims about what constitutivism can accomplish are built into its definition. For example, one might define constitutivism as a program for answering, in a decisive fashion, what Korsgaard has dubbed "the normative question". ${ }^{3}$ Or one might define constitutivism so that it is committed to closing the alleged gap between is and ought in some way. ${ }^{4}$

These are some of the most prominent ways of motivating constitutivism. But it would be a mistake to treat such claims as part of the definition of what constitutivism is. For constitutivists disagree greatly about what exactly constitutivism can accomplish. And it is far from clear that the appeal of

1 The association of Kant and constitutivism is due above all to the work of Korsgaard - see for example Korsgaard(1996, 2008, 2009). A close second in significance in this regard is Velleman(2000, 2009). For some of the other (Kantian and anti-Kantian) variants on the constitutivist idea, see Foot(2003), Thomson(2008), Thompson(2008), Smith(2012,2013), James(2012), Walden(2012), Katsafanas(2013), Setiya(2013), and Lavin(forthcoming). Say something about "constitutivism" in other areas?

2 I've discussed this question previously (with more of a contemporary focus) in Schafer(2015-a,b, 2018-a). See also the discussion of Sensen(2013), which arrives at a somewhat similar conclusion, albeit in a different systematic context.

${ }^{3}$ Korsgaard herself is often read this way, although the precise sense in which this is true of her work is open to some dispute.

${ }^{4}$ Compare Lindeman(2017) 
constitutivism stands or falls with its ability to perform any particular metaethical task. ${ }^{5}$ Thus, in considering the merits of constitutivism, it is important to keep the mode of philosophical explanation which is essential to constitutivism separate from the philosophical work this style of explanation can accomplish. Of course, the constitutivist mode of explanation must do something to be of philosophical interest. But just what it can do should be left open by its definition.

Given this, some of the most prominent objections to constitutivism are best understood - not as objections to constitutivism as such - but rather as objections to claims about what constitutivism can accomplish. This is particularly true of the "shmagency objection" made famous by Enoch's discussion of Korsgaard. ${ }^{6}$ For even if we think that Enoch is right about what the possibility of shmagency shows, this is at most an objection to certain claims about constitutivism's capacity to decisively foreclose normative questions. Thus, so long as we do not think the attractiveness of constitutivism depends upon its ability to perform this task, worries about "shmagency" need not be fatal to the constitutivist. ${ }^{7}$

This is significant, because I think it is clear that Kant's interest in broadly constitutivist ideas was not motivated by the use of these ideas that Enoch targets. For example, Kant certainly did not intend his account of the relationship between moral requirements and practical reason to provide us with a dialectically effective response to all forms of moral skepticism. For Kant's official position is that our cognitive access to the nature of practical reason occurs via our consciousness of the moral law (as the fundamental principle of pure practical reason). ${ }^{8}$ Thus, according to Kant's official account, it is our consciousness of the moral law that comes first in the order of cognition. As a result, if there are indeed constitutivist elements within Kant's account, their purpose is not to, say, help us answer the question: "Why be moral?"

This is one sense in which my definition of constitutivism is purposely broad. But there is a second issue on which this definition is intentionally silent - namely, the question of exactly which X's this definition applies to. For example, my definition of constitutivism says nothing about which description of my nature it is which grounds the fundamental norms that apply to me.

It is on this point that constitutivism breaks into a wide range of sub-genres. For example, Aristotelian constitutivists focus on my nature as a human being. While "Humean" constitutivists focus on my nature as a rational being in a some rather minimal sense of "rational".

Of these forms of constitutivism, our focus will be constitutivism in its Kantian form. Kantian constitutivism is often described as treating our nature as agents as what explains the fundamental norms that apply to us. For example, Kantian constitutivists are often thought of as grounding facts about normative reasons in facts about the nature of agency:

\footnotetext{
${ }^{5}$ For more modest conceptions of constitutivism's role, see Schafer(2015-a, 2018-a), Smith(2012, 2013), Lord and Sylvan(forthcoming).

${ }^{6}$ For the canonical statement of the shmagency worry, see Enoch(2006, 2011). For further discussion, see Ferraro(2009), Tiffany(2012), and Silverstein(2015), amongst others.

${ }^{7}$ See Schafer(2015a,b). For a more involved defense of this point, see Paakkunainen(2018). That being said, the "shmagency point" might point to certain explanatory limitations of constitutivism - limitations that could have much broader significance for the constitutivist strategy. My aim here, of course, is not to settle these debates.

${ }^{8}$ Here I take the second Critique to provide Kant's canonical statement of his views on this issue. I don't believe this should be especially controversial. Unfortunately there's no time here to discuss the relationship between the second Critique and the Groundwork, where Kant may flirt with aims more like those that Enoch targets.
} 
Agency-First Constitutivism: The fundamental norms that apply to us are grounded in our nature as agents. ${ }^{9}$

This remains the dominant way of formulating Kantian constitutivism. But, as I've argued elsewhere, such formulations obscure some of the important advantages of Kantian forms of contitutivism. ${ }^{10}$ For example, a focus on agency can suggest a view that is best suited to the practical, as opposed to the epistemic, domain. And so this focus can hinder the development of a truly unified account of both theoretical and practical norms along constitutivist lines. Similarly, it can easily make the Kantian view seem implausibly self-obsessed - concerned with the project of selfunification or self-governance as opposed to the wider world. And it can also hide from our eyes some of the resources the Kantian has for explaining the normative significance of moral and epistemic principles.

Of course, much more would need to be said about each of these points to make them compelling. ${ }^{11}$ I note them here solely to give the reader a sense of why it seems to me that Kantian constitutivism is best characterized as treating as fundamental - not our nature as agents - but rather our nature as rational beings, or creatures endowed with the capacity of reason:

Reason-First Constitutivism: The fundamental norms that apply to us are grounded in our nature as rational beings or creatures with the capacity of reason.

In reading Reason-First Constitutivism, it is important to remember that the notion of reason at issue here (for the Kantian at least) is equally theoretical and practical. So it includes within its scope, our powers of practical reason and rational agency. In this sense, Reason-First Constitutivism is a natural development of Agency-First Constitutivism - one which aims to make explicit that the starting point of the Kantian account should be a unified conception of reason as both theoretical and practical.

Indeed, as we will see, the most Kantian forms of Agency-First Constitutivism and Reason-First Constitutivism converge with one another, once fully developed. But nonetheless, I will focus on Reason-First Constitutivism here. This framing is particularly helpful in a historical context, since it fits better with Kant's own discussion of these issues. In particular, as we will see, Kant's constitutivism is best understood as an instance of a more general "capacity-first" approach to philosophy. And the capacity that is most fundamental, for Kant, in developing that approach is just the faculty of reason itself.

As a result, what is truly most fundamental to Kant's constitutivism is a certain conception of the faculty of reason. Now, to be fair, reason is for Kant the faculty for a particular form of agency. But if our aim is to understand Kant's form of constitutivism, it is more accurate to describe it as a form of Reason-First Constitutivism as opposed to trying to translate Kant's claims about reason into a corresponding form of Agency-First Constitutivism, even if there is a sense in which such a translation is possible.

\footnotetext{
9 Again, this sort of view is most closely associated with the work of Korsgaard and Velleman. For related views, see Bagnoli(2011, 2013), James(2012), Smith(2012, 2013), and Kastafantsas(2013), amongst others.

${ }^{10}$ For more discussion of this point, see Schafer(2018-a, forthcoming-a). Compare Walden(forthcoming).

${ }^{11}$ For a fuller development of this view, see Schafer(2018-a, forthcoming-a,c)
} 


\section{The Foundational Role of Capacities within the Critical Philosophy}

With this bit of contemporary context in mind, let's turn to the interpretative questions which will be this essay's focus. As noted above, in doing so, I will begin somewhere rather non-obvious, given our topic. In particular, I want to start - not by discussing Kant's explicit discussion of broadly meta-normative questions - but rather with some more general questions concerning Kant's philosophical methodology during the critical period.

To understand why these more general questions are relevant, it will be helpful to begin with Kant's conception of the shape philosophy must take if it is to be rationally satisfactory. As is familiar, one of reason's fundamental demands, according to Kant, is for "systematic unity". Speaking very roughly, this means that reason will only be satisfied with a body of cognitions insofar as they form an organized unity as opposed to a "mere aggregate":

... systematic unity is that which first makes ordinary cognition into a science, i.e., makes a system out of a mere aggregate of it ... (A832/8860)

What gives cognitions this sort of unity is the fact that they are grounded in more fundamental principles or ideas, which provide them with systematic structure. Just what this requires is a complicated question, which I cannot discuss in detail here. ${ }^{12}$ But one important implication of these ideas is that philosophy will only be rationally satisfactory insofar as it forms a unified system of judgments or cognitions, which must be based on certain a priori principles or ideas. Thus, for Kant, philosophy is only possible insofar as we can locate principles or ideas that can play this foundational, unifying role - not just with respect to this or that particular area of inquiry, but also with respect to all of philosophy or, indeed, human cognition in general:

Philosophy in sensu scholastico involves two things, (1.) A sufficient supply of cognitions of reason. (2.) A correct connection of these, or a system. For a system is the connection of many cognitions in accordance with an idea. (24:799)

The two must be united; for without cognitions one will never become a philosopher, but cognitions alone will never constitute the philosopher either, unless there is in addition a purposive combination of all cognitions and skills in a unity, and an insight into their agreement with the highest ends of human reason. (9:25)

But where is philosophy to find these unifying principles or ideas? Kant's answer to this question is heavily constrained by another of his fundamental methodological commitments during the critical period. In particular, partially in the wake of his struggle to explain the possibility of synthetic a priori principles, Kant become convinced that human insight bottoms out in a set of basic faculties - faculties which cannot be explained in more fundamental terms, but which nonetheless provide a non-arbitrary basis for further explanations:

But all human insight is at an end as soon as we have arrived at basic powers or basic faculties; for there is nothing through which their possibility can be conceived, and yet it may not be invented and assumed at one's discretion. (5:46-7, my emphasis)

12 I discuss this further in Schafer(forthcoming-d). For some related discussion of these issues, see Ameriks(2011), Guyer(2008), Wood(1999), Grier(2005), Watkins(2018), and Willashek(forthcoming). 
We'll return in a moment to why Kant believes that our basic rational capacities - and only those are capable of playing this role. But for now, I want to focus on its implications both for the order of human cognition (the ratio cognoscendi of things) and for the order of metaphysical explanation (their ratio essendi).

On the one hand, Kant is claiming here that, at least within the limits of human cognition, our ability to have insight into the metaphysical explanation of things (their ratio essendi) comes to an end with the nature of certain basic rational faculties. Thus, at least for us, the nature of these faculties takes priority in the order of metaphysical explanation. In other words, for us, philosophical explanations bottom out in the nature of these capacities.

But these basic rational capacities, in virtue of their self-conscious character, also provide human cognition with a set of cognitive fixed points - that is, with something that may not invented in an arbitrary or discretionary fashion. Thus, the self-consciousness of these basic faculties - or, more precisely, the self-conscious character of their activities - provides us with something that takes priority in the order of cognition (ratio cognoscendi) as well. In a moment, we'll discuss how Kant conceives of this more fully. But the important point at present is just that these capacities (as selfconscious) also serve, according to Kant, as something that is cognitively or epistemically fundamental for us.

Given all this, it is not hard to guess where Kant will locate the fundamental principles that systematic philosophy requires. In particular, at least for the critical Kant, these principles must located in our basic rational faculties. Thus, it is no surprise to discover that, at least during the critical period, Kant consistently maintains that the foundations of a genuine philosophical system or science can only be provided by the fundamental faculties of the mind and the principles that govern these faculties:

In this way the a priori principles of two faculties of the mind, the faculty of cognition and that of desire, would be found and determined as to the conditions, extent, and boundaries of their use, and a firm basis would thereby be laid for a scientific system of philosophy, both theoretical and practical. (5:12, my emphasis, compare 5:169)

The concepts of nature, which contain the ground for all theoretical cognition a priori, rested on the legislation of the understanding. ... The concept of freedom, which contains the ground for all sensibly unconditioned practical precepts a priori, rested on the legislation of reason. $(5: 176)$

As we'll discuss more fully, this mode of explanation is possible for Kant because these basic rational capacities do in fact provide us with just the sort of principle that is required here. Given this, one of the main tasks of the "critique" of our rational faculties is to identify the principles that are characteristic of their activities. In other words, as Kant puts it, "critical philosophy" must deliver to "doctrinal philosophy" the principles that will serve as doctrinal philosophy's foundation. For example, the critique of practical reason both provides us with clear consciousness of the principles of pure practical reason and their limits, and delivers these principles to moral philosophy to serve as the foundation for a systematic understanding of moral "doctrine". 
In this way, while the project of critique is often thought of in terms of the negative task of determining the proper limits of our rational faculties, critique also has a crucial positive task as well namely, to identify the principles that will serve as the foundation for "doctrinal" philosophy, by tracing them to their roots in our rational faculties:

The critique of the faculties of cognition with regard to what they can accomplish a priori has, strictly speaking, no domain with regard to objects, because it is not a doctrine, but only has to investigate whether and how a doctrine is possible through it given the way it is situated with respect to our faculties. (5:176, compare $20: 195,20: 202)$

There's much more to be said about these ideas, but the most important points for present purposes are the following. First, philosophy for Kant can be systematic only insofar as it is grounded in a unified system of non-arbitrary principles. Second, for Kant, these principles can only be provided by our basic rational capacities. And, third, as a result, a truly systematic philosophy is possible only insofar as our rational faculties themselves form a systematic unity:

There is thus revealed a system of the powers of mind, in their relation to nature and freedom, both of which have their own special, determining principles a priori and therefore constitute the two parts of philosophy (the theoretical and the practical) as a doctrinal system ... (20:247, my emphasis, compare 5:169)

Now, in saying all this, it is important to stress that for Kant (unlike for many of the German Idealists who followed him) to say that our rational faculties form a system is not to say that these faculties are reducible to some single common explanatory principle. Rather, Kant stresses that there are limits to this sort of reduction (at least from a human perspective):

... all faculties or capacities of the soul can be reduced to the three that cannot be further derived from a common ground: the faculty of cognition, the feeling of pleasure and displeasure, and the faculty of desire. $(5: 177)$

Thus, although Kant is deeply committed to a system of our rational faculties, he just as deeply rejects the project of reducing this system to a single ur-faculty or -principle. ${ }^{13}$ The question of the compatibility of these two ideas will, of course, be the focus of a good deal of German philosophy in the decades after Kant. But for our purposes here, it is sufficient to keep these two commitments in mind.

\section{Which Faculties? Transcendental Arguments and Self-Consciousness}

Of course, this sort of "capacities-first" approach to philosophy invites many questions. For example, how are we to determine which faculties are to have this sort of foundational status? And how, in particular, can we do so in a non-arbitrary and rationally satisfying fashion?

In the literature on Kant, and indeed in Kant himself, one can find at least two basic strategies for responding to these questions. First, as I have already suggested, it might be that we are entitled to take certain rational faculties for granted in our philosophical theorizing in virtue of the self-conscious

\footnotetext{
13 Thus, in some ways, Kant is here closer to Hegel's holistic picture of the interdependence of the elements of a system
} than he is to Reinhold or Fichte's emphasis on locating some absolute first principle. 
character of those very faculties. Or, second, it might be that the introduction of these faculties into our philosophical system is justified via some sort of transcendental argument, which shows them to be necessary conditions on even more basic features of experience.

It is hard to deny that both of these strategies have a role to play in Kant's overall philosophical methodology. But nonetheless it seems to me that it is the first that provides the ultimate foundations for the critical philosophy. To see why, it will be helpful to consider one of the best recent statements of how the other interpretative option here might go. The discussion I have in mind appears in Haag(2014). There Haag writes:

The existence of faculties, from the perspective of transcendental philosophy, likewise has to be established by reflecting on the conditions of the possibility of conscious experience. ... it is the function that transcendental reflection reveals as needing to be fulfilled that justifies the introduction of a particular faculty. (199)

In other words, for Haag, the introduction of any faculty - even the most basic - into our philosophical system must, for Kant, be justified by some further piece of "transcendental reflection".

I think Haag is perfectly correct in claiming that something like this strategy is used at times by Kant. But I doubt that this accurately characterize how Kant views our entitlement to appeal to the existence of certain very basic rational faculties. The reason for this is quite simple. For suppose we ask Haag how he understands the starting point of the sort of "transcendental reflections" which (according to him) justifies the introduction of any faculty into the critical system.

In answering this question we must, of course, remember that the starting point of these reflections is not, for Kant, an extremely minimal sort of self-consciousness. Rather, unlike (say) Reinhold or Fichte, Kant begins his "transcendental reflections" in all three Critiques with something more robust. For example, the starting point of Kant's "transcendental reflections" in the first Critique is not the bare fact of self-consciousness, but rather the fact that we are creatures who are capable (at least in principle) of empirical cognition of a fairly non-trivial sort. And plainly something similar is true of the both the second and third Critiques as well.

Given this, it is only fair to ask Haag how we are to know that we are creatures with the capacity for these sorts of non-trivial cognitive achievements. For example, how can we know that we are capable (at least in principle) of empirical cognition in the sense the first Critique takes for granted? Not, at least for Kant, through a further, more basic piece of "transcendental reflection" of the sort Haag describes. Rather, for Kant, it seems clear that we can know that we are creatures with a capacity for (say) empirical cognition simply in virtue of the self-conscious character of our basic cognitive capacities.

In this way, at least in the context of Kant's views, there does not seem to be any real alternative to the idea that the existence of some basic rational faculties can be established in virtue of their selfconscious character. As we'll discuss in the next section, this means that the foundations of philosophy are, for Kant, provided by the kind of active self-consciousness we possess as creatures with 
these basic rational capacities. ${ }^{14}$ That is, transcendental philosophy ultimately begins with that consciousness of their own activities which is constitutive of these capacities as self-conscious. Then, from this starting point, the critical philosopher can make this consciousness more explicit, and then proceed to use this explicit consciousness as a foundation for further philosophical theorizing. But the ultimate foundations of the critical philosophy are provided by this consciousness of the activities of our own rational faculties. Thus, as Kant says about these foundations:

Nothing here can escape us, because what reason brings forth entirely out of itself cannot be hidden, but is brought to light by reason itself as soon as reason's common principle has been discovered. (Axx, compare 28:1051)

\section{Two Brief Illustrations: Transcendental Idealism and the Fact of Reason}

This way of thinking about Kant's basic methodological commitments is, I think, quite helpful for thinking about many of the most vexed issues in Kant interpretation. For once one recognizes that Kant is working within this "capacities-first" framework, it is easy to find it in action throughout his critical works.

For example, from this perspective, we can approach the familiar issue of Kant's Transcendental Idealism from a more systematic perspective, by seeing it as one (particularly important, to be sure) application of this "capacities-first" mode of philosophical explanation. After all, the whole point of Transcendental Idealism is precisely to explain the (formal) nature of spatial-temporal reality by grounding this reality in the formal features of our faculties for empirical cognition.

Of course, just what this mode of explanation involves - especially from a metaphysical perspective - has been the subject of endless debate. My own view, in brief, is that while Transcendental Idealism does commit Kant to the existence of some sort of metaphysical dependence of the form of the sensible world on the form of our cognitive faculties, the precise nature of this dependence relation is left highly indeterminate by Kant's theoretical philosophy. Thus, on my reading, it is only with the practical philosophy that we begin to see anything like a developed account of how the sensible world depends upon our rational faculties.

In any case, the topic of this essay is not Kant's Transcendental Idealism. So the important point for present purposes is simply that Transcendental Idealism provides us with a central example of the capacities-first approach to philosophy in action. And this aspect of Kant's philosophical methodology is also clearly on display at the foundations of Kant's practical philosophy as well. Consider, for example, Kant's discussion of the famous (or infamous) Faktum der Vernunft.

This section of the second Critique has often been regarded as an unhappy retreat by Kant into a precritical form of moral dogmatism. But when read correctly, Kant's appeal in it to a basic consciousness of the moral law appears in a very different light. In particular, far from being a retreat into some sort of rational intuitionism, the Faktum der Vernunft is best understood precisely as

\footnotetext{
${ }^{14}$ Note that this means that to say that philosophy rests on our capacity for reason is not to say that it rests on the mere concept of this capacity - which, on its own, is inadequate (for Kant) to play the role required here. (6:26) For more on the ability of this sort of consciousness to provide us with something like cognition of our own freedom, see Schafer(2018b).
} 
an instance of the capacity-first approach to philosophy - an approach to philosophy which is central (for Kant) to the difference between transcendental philosophy and dogmatic rationalism.

Indeed, the Faktum der Vernunft is especially interesting here because it clearly displays the priority of our basic rational faculties in both the order of cognition and the order of metaphysical explanation. On the one hand, in the Faktum der Vernunft, Kant treats our consciousness of freedom as based in the self-consciousness of pure practical reason itself - a self-consciousness that involves a consciousness of the moral law as the principle of practical reason. So, in this sense, the order of cognition in work in this passage begins with the self-consciousness of practical reason, just as we would have expected from our discussion.

But, at the same time, Kant also treats the nature of practical reason as fundamental with respect to the order of philosophical explanation here as well. For, in claiming that autonomy is the ratio essendi of morality, Kant claims that it is the nature of practical reason - and, in particular, its character as autonomous - which explains why we are subject to the moral law in the first place. So here different aspects of practical reason as a faculty take (first) cognitive and (second) metaphysical priority within the contours of Kant's account.

\section{Principles: How Rational Capacities Make Philosophy Possible}

If all this is correct, then the viability of Kant's philosophical project depends, at a very fundamental level, on the ability of our basic rational capacities to play the role we have been describing. To do so, at least two things must be true of them. First, they must provide us with principles that can play a foundational explanatory role within philosophy. And, second, these principles must (at least under advantageous conditions) be accessible to us in virtue of the fact that we are rational creatures who possess the relevant rational capacities.

One source of support for the present interpretation is that Kant's conception of rational faculties is, indeed, perfectly suited to play these two roles. In fact, as we will see, these roles are closely connected for Kant - since the self-conscious character of our faculties is, according to Kant, closely linked to the sense in which their activities are governed by principles of a non-trivial sort.

To explore this, let's begin by considering Kant's conception of a rational faculty in more detail. As Kant understands them, capacities are individuated by principles which (in a manner that will become clear) both describe and govern their activity. For present purposes, these principles can be thought of as characterizing the activity that is distinctive of the faculty in question. The principle of a faculty, in other words, tells us what this faculty (as such) does - be this synthesis or judgment or inference or the determination of the will or the formation of new concepts. ${ }^{15}$

As this indicates, there is at least a weak sense in which every genuine faculty is "active" for Kant. For the activity of any genuine faculty is governed by an internal principle which characterizes its distinctive forms of activity. Of course, just how robust this "activity" is - and, in particular, whether it is conditional on something external to the faculty - will vary from faculty to faculty. So, for example, the "activity" of sensibility as a faculty will be conditional, in different ways, on both the affection of the subject by the object and the higher ends and activities of the understanding,

${ }^{15}$ Compare Reath(2006,2013) and Herman(1993,2007) on the "power-conferring" or "power-constituting" character of principles in Kant. 
judgment, and (ultimately) reason. But nonetheless, sensibility still does possess an internal principle in this very general sense.

In this way, for Kant, every faculty is paired with an internal principle that explains how this faculty functions insofar as it is free from abnormal, external "hindrances". As we will see, this idea is very significant for Kant's understanding of the "sources of normativity". But before considering this connection, we need to discuss how these internal principles play the two roles required by the capacities-first approach to philosophy sketched above.

In order to play the first of these roles, these principles must be robust enough to serve as the explanatory foundations for both theoretical and practical philosophy. But, to play the second, they must also be something we can have access to simply in virtue of possessing the self-conscious capacities they govern. Unfortunately, at least at first glance, these roles seem to push us in opposite directions. After all, the more robust these principles are, the less plausible it is that an awareness of them is somehow "implicit" in the possession of the relevant rational capacities. So, it is only fair to wonder whether it is possible to combine these two roles in the manner Kant's methodology seems to require.

Giving a fully satisfactory response to this concern would be a book-length project. So I cannot pretend to present such a response here. ${ }^{16}$ But I do want to say a bit more about these issues, before moving on, to give the reader some sense of how Kant's conception of rational capacities is designed to deal with them. ${ }^{17}$

In doing so, I'll focus on the element of Kant's conception of our capacities that is most immediately relevant to the topic of this essay - namely, its teleological dimension. This dimension is clear from Kant's consistent use of teleological terms to describe our faculties. For example:

The final aim to which in the end the speculation of reason in its transcendental use is directed concerns three objects: the freedom of the will, the immortality of the soul, and the existence of God. (A798/B826, my emphasis, in a section entitled "On the ultimate end of the pure use of our reason")

... the lawful unity in a combination that we cognize as in accordance with a necessary aim (a need) of the understanding ... (5:184, my emphasis)

... the understanding, which is aimed at an end that is necessary for it, namely to introduce into it unity of principles ... (5:187, my emphasis)

Similarly, Kant often uses the closely related notion of an "interest" to characterize our faculties:

To every faculty of the mind one can attribute an interest, that is a principle that contains the condition under which alone its exercise is promoted. ... That which is required for the

\footnotetext{
${ }^{16}$ But see Schafer(forthcoming-d)

${ }^{17}$ Given these limitations, I'll mostly be leaving the hylomorphic dimension of Kant's conception of our faculties to the side here, although this is absolutely central to the explanatory project once it is fully developed. Compare e.g. Willashek(forthcoming). For an insightful development of these aspects of Kant in the context of contemporary epistemology, see Kern(2018).
} 
possibility of any use of reason as such, namely, that its principles and affirmations must not contradict one another, constitutes no part of its interest but is instead the condition of having reason at all; only its extension, not mere consistency with itself, is reckoned as its interest. $(5: 120)$

Reason is driven by a propensity of its nature to go beyond its use in experience, to venture to the outermost bounds of all cognition by means of mere ideas in a pure use, and to find peace only in the completion of its circle in a self-subsisting systematic whole. Now is this striving grounded merely in its speculative interest, or rather uniquely and solely in its practical interest? (A797/B825, my emphasis)

Given such passages, there is little doubt that Kant's conception of our faculties is teleological in some sense. But how exactly should these teleological characterizations be understood?

Well, Kant's official definition of an "end" is the following: "the concept of an object insofar as it at the same time contains the ground of the reality of this object." (5:180, compare 4:427, 6:381) So, by the lights of this definition, to attribute an end $\mathrm{X}$ to something seems to involve regarding that thing as related to some representation of $\mathrm{X}$, a representation which functions as the ground of the existence of X. In other words, to represent our rational capacities as having ends seems, for Kant, to involve representing the activities of these faculties as governed by a representation of the faculty's end in some sense. ${ }^{18}$

Moreover, unlike in the case of artifacts, it seems clear that the end in question is sometimes internal to the faculty in question here. ${ }^{19}$ And, unlike in the case of natural organisms, in making such claims about our faculties, Kant does not seem to be doing so merely for "regulative" purposes by means of an "analogy". ${ }^{20}$ Rather, it seems clear that Kant means to attribute ends to our faculties in a stronger, less analogical sense. ${ }^{21}$

So how should we think about Kant's attribution of teleological structure to our faculties? It is helpful here, I think, to understand our faculties as having a teleological structure that is formally akin to the teleological structure of natural organisms, only without the restrictions that Kant places

\footnotetext{
${ }_{18}$ Here there are interesting connections with the contemporary literature on the "taking condition". See Boghossian(2008,2014). Unfortunately I can't explore these connections in more detail here, but see Neta(forthcoming) a contemporary view that share some features with the view I'll be attributing to Kant.

${ }^{19}$ This is clearly true of reason in particular. Whether the ends of other rational faculties - such as the understanding are internal to those faculties is a complicated question, since these ends do in some sense depend on reason's ends. 20 See 5:360. Compare:
}

Nevertheless, teleological judging is rightly drawn into our research into nature, at least problematically, but only in order to bring it under principles of observation and research in analogy with causality according to ends, without presuming thereby to explain it. It thus belongs to the reflecting, not to the determining power of judgment. ... If, however, we were to base nature on intentionally acting causes, hence were to ground teleology not merely on a regulative principle for the mere judging of appearances, ... it would introduce a new causality into natural science, which, however, we merely borrow from ourselves and ascribe to other beings, yet without wanting to think of them as similar to ourselves. (5:360-1, my emphasis, compare 5:375)

${ }^{21}$ For discussion, see (e.g.) Guyer(2008), Ginsborg(2015), and Breitenbach(2014) (amongst others). I am most sympathetic to Breitenbach's treatment of these issues, which focuses on the analogy between natural teleological systems and the teleology of practical reason. 
on our use of teleological concepts in the biological case. ${ }^{22}$ In other words, for Kant, our faculties seem to have the formal structure that natural organisms would have if we were entitled to think of such organisms using our teleological concepts in a more than merely analogical fashion. ${ }^{23}$

What this means is that, like natural organisms, our faculties must be thought of as self-organizing wholes. ${ }^{24}$ But, unlike in the biological case, a faculty's activities are literally guided by an end which is internal to that very faculty. So how are we to make sense of this, without committing Kant to an implausibly intellectualized conception of our rational capacities?

At this stage, it is helpful to return to one of the passages cited above, in order to note something puzzling about it:

To every faculty of the mind one can attribute an interest, that is a principle that contains the condition under which alone its exercise is promoted. ... (5:120, my emphasis)

Here Kant identifies the interest of a faculty with the "condition under which alone its exercise is promoted". This should strike many contemporary readers as rather odd. But for someone, like Kant, steeped in the broadly Aristotelian context of post-Leibnizian German philosophy, it would have in fact seemed quite natural. For part of a broadly Aristotelian conception of our capacities is the idea that a genuine capacity must, in a sense, aim at its own exercise or activity. ${ }^{25}$

On this conception, any faculty can be thought of as having the "end" of actualizing itself via its own characteristic activity. ${ }^{26}$ In other words, as Reath nicely puts the point, any such "capacity is constitutively aimed at its own proper exercise". ${ }^{27}$ If this is right, then to say that a faculty represents its own end is just to say that it represents its own characteristic activity and that this representation ideally guides that activity. So, to say that a faculty represents its own end is just to say that it has an active or productive consciousness of its own activity. In this sense, as noted above, the teleological character of our rational faculties for Kant is fundamentally a product of the manner in which they are self-conscious.

Is such a conception of our rational capacities overly-intellectualized? Answering this question lies outside the scope of this essay. But it is worth stressing here that, in attributing an active representation of its own activity to each rational faculty, we are not saying that we are normally explicitly conscious of this representation. ${ }^{28}$ Rather, as Kant notes, "For common cognition it is not necessary that we be conscious of these rules and reflect on them.” (24:27, compare A78/B103)

\footnotetext{
22 Compare the very helpful discussion in Fugate(2014).

${ }^{23}$ See, again, Breitenbach(2014)'s discussion of these issues. Here it is important to stress that it is of course true that there are real limits, according to Kant, to our ability to achieve anything like genuine cognition (Erkenntnis) of the teleological structure of our faculties through the use of these concepts. For further discussion, see Schafer(2018-b). ${ }^{24}$ This brings us back to the hylomorphic characterization of these faculties we set aside above. As Kant stresses, to be self-organizing whole something must possess a "a self-propagating formative power" - a power to bring form to itself. (5:374)

${ }^{25}$ For discussion of this idea, see Herman(2007), Reath(2013), and especially Engstrom(2009). Compare Rödl(2018).

26 This point has its sensible manifestation in Kant's discussion of judgments of beauty within the third Critique - and, in particular, in that discussion's claim that we take pleasure in the free-play of our basic rational faculties. Such pleasure, I believe, is best understood as the sensible manifestation of the interest that any faculty must have in its own actualization or exercise.

27 Reath(2013), 577.

${ }^{28}$ Compare Cohen(2009), Longuenesse(2017).
} 
In addition, we need not understand the idea of each faculty as possessing a representation of its own activity to imply that this representation is something over and above the activities of the faculty. Rather, this "representation" may be implicit in or constitutive of these very activities themselves in some way. ${ }^{29}$ In other words, while it is clear that a rational faculty must, for Kant, possess a guiding consciousness of its own characteristic activity, this awareness need not involve a distinct representation over and above its activities.

\section{Kant's Constitutivism: How Rational Faculties Ground Norms}

Unfortunately, pursuing these questions further would lead us away from this essay's topic. So I want to turn back now to Kant relationship to constitutivism - and how this relates to the broader theme of Kant as a capacities-first philosopher.

To consider these questions, let's turn (at last) to Kant's explicit account of the nature of normative propositions or imperatives. This account is well represented by passages like the following:

A practical rule is always a product of reason because it prescribes action as a means to an effect, which is its purpose. But for a being in whom reason quite alone is not the determining ground of the will, this rule is an imperative, that is, a rule indicated by an 'ought', which ... signifies that if reason completely determined the will the action would without fail take place in accordance with this rule." (5:20, my emphasis, compare 4:449)

As this make clear, imperatives for Kant apply only to beings who possess reason, but in whom this faculty's proper operation may be hindered by the external influence of sensibility. More precisely, for Kant, an imperative applies to some agent just in case it accurately characterizes what they would do if their rational faculties were free of any such "external hinderance". ${ }^{30}$

For example, the moral law can be thought of in at least two ways. First, it may be thought of as a principle which describes how practical reason functions insofar as it is free of any illicit sensible influence. ${ }^{31}$ In this sense, it is "descriptive" or "constitutive" of practical reason - although, of course, what it is describing is a teleologically-structured faculty. But, with respect to creatures in whom reason can be interfered with by sensibility, the moral law may also be represented as an imperative - namely the categorical imperative in its various formulations. ${ }^{32}$ Thus, when we consider reason in the context of a sensibly conditioned finite subject, the principle of reason as a faculty will

\footnotetext{
${ }^{29}$ See Boyle(2009), Burge(2010), and Longuenesse(2017).

${ }^{30}$ Compare Marshall(forthcoming).

31 As Kant stresses in the Religion, exactly how this sort of "hinderance" occurs is (at least in some cases) "inscrutable" for us - given that it must leave evil actions imputable to us and so traceable to our spontaneous power of choice. (6:21) Here, as in many places, we come up against the limits of our comprehension of the relationship between our sensible and intellectual faculties. Given this, it is important to see Kant's evolving views concerning the relationship between practical reason, the will, and the power of choice as making room for this "inscrutability" as opposed to explaining what remains (for Kant) inscrutable. And, even in the Religion, Kant continues to stress that deviations from the moral law (i) are not internal to practical reason and (ii) are only possible insofar as our sensible nature provides the power of choice with an incentive that can conflict with the incentive of the moral law.

32 Compare 5:403-4.
} 
always be both constitutive (of reason's exercise insofar as this is free of illicit sensible influences) and normative (for the subject's thoughts and actions given that they are subject to such influences). ${ }^{33}$

Crucially, this point generalizes to any rational faculty whatsoever. In other words, in this sense, imperatival principles are equally characteristic of both theoretical and practical faculties. For the principle characteristic of any (human) rational faculty - be it theoretical or practical - can be expressed as either a theoretical claim about how this faculty functions (when "left to its own devices") or a normative claim about how it ought to function in rationally imperfect creatures like ourselves.

For example, Kant similarly stresses that errors of the understanding are always the product, not of the understanding itself, but rather of the "unnoticed influence of sensibility" upon us. ${ }^{34}$ Thus, much like the moral law, the principles of the understanding can be regarded either as characterizing how the understanding operates insofar as it is free of the "unnoticed influence of sensibility" or as imperatives which characterize how the understanding ought to function in creatures in whom such interference is possible. ${ }^{35}$

Thus, we can now see that a very general sort of meta-normative constitutivism follows from Kant's conception of our rational capacities, when it is paired with his account of imperatives or normative claims. For, given these commitments, the normative principles that apply to the activities of any rational faculty will, for Kant, be grounded in that faculty's nature - and in particular the nature of its characteristic activity. Or, more precisely, the principles in question will be grounded in the nature of the relevant rational capacity - while the status of these principles as normative (as opposed to merely descriptive) will be grounded in the fact that this rational capacity is not free of external hinderance.

In this way, Kant is indeed deeply committed to a form of constitutivism, which we might characterize as follows:

Rational Capacities Constitutivism: The normative principles that apply to the activities of any rational capacity are grounded in the nature of that capacity.

This principle is quite similar to Reason-First Constitutivism, but it does differ from that principle insofar as it treats as fundamental all of our rational faculties, as opposed to focusing on reason in particular. But remember that our rational capacities must themselves form a system for Kant. And this system must be a teleological one. That is, any system of rational capacities must also be a system of the ends of these capacities. And in any such system, it is plain that ends of reason in particular must take precedence for Kant. For reason is of course autonomous for Kant - so it's

\footnotetext{
${ }^{33}$ In his insightful (if somewhat Sellarsian) discussion, Pollok(2017) also claims that such principles are both constitutive and normative, but he does not explain this in the manner I do here. This leads him to fail to recognize that this basic framework applies to the principles of logic (again, insofar as they are realized by a finite, sensibly conditioned subject). The ultimate source of these difficulties seems to me to be Pollok's unease with the more metaphysical dimensions of Kant's views. This resolutely non-metaphysical reading was, of course, dominant for much the $20^{\text {th }}$ century, but one of the main advances of the last few decades of Kant scholarship seems to me to have been a recognition of the ways in which it misses some of what mattered most to Kant.

34 A294/B350-1.

35 Compare McDowell(2006), Engstrom(2009) and Kern(2018). As I discuss in Schafer(forthcoming-d), this has important implications for the extensive debate about whether logic is normative for Kant.
} 
ends cannot be conditioned by the ends of any other faculty. Thus, if our faculties are to form a rational system, it must be reason's ends in particular that serve as the foundation of this system's teleological unity.

For this reason, it can only be reason that ultimately determines the proper scope of the activities of all of our rational faculties. Or, in other words, it is the ends of reason that form the foundation for the system of our rational faculties. ${ }^{36}$ Thus, in the end, Kant is indeed best read - not just as a proponent of Rational Capacities Constitutivism - but also as a proponent of Reason-First Constitutivism. ${ }^{37}$ For it is ultimately reason, and its characteristic activities or ends, which, for Kant, determine the norms which govern the proper operation of all our various rational faculties:

Reason-First Constitutivism: The most fundamental norms that apply to us are grounded in our nature as rational beings or creatures with the capacity of reason.

\section{Kant's Constitutivism and the Unity of Reason}

Of course, Reason-First Constitutivism leaves the nature of the capacity of reason entirely open, and so, on its own, tells us very little about the norms which follow from this approach. As a result, in order to understand the implications of Kant's commitment to this form of constitutivism, we would need to say much more about the ends and activities that are characteristic of reason as a capacity for Kant.

Unfortunately, Kant describes reason's characteristic activities in a variety of ways - including descriptions of reason: (i) as the faculty for (mediate) inference, (ii) as the faculty of principles, (iii) as the faculty for systematic unity, (iv) as autonomous, and (v) as faculty for what Kant calls comprehension. So, from an interpretative perspective, this question is anything but simple. As a result, I won't pretend to offer anything like a comprehensive answer to them here. ${ }^{38}$ But I do want to say a bit more about this - both to put a little meat on the bones of the reading of Kant we have been developing and because doing so will help to clarify the relationship between Kantian forms of Reason-First Constitutivism and Agency-First Constitutivism.

With these aims in mind, I'm going to focus here on three of Kant's characterizations of reason in particular:

(i) Reason's proper activity lies in (theoretical and practical) cognition from principles.

(ii) Reason's proper activity lies in (theoretical and practical) comprehension.

(iii) Reason's proper activity lies in autonomy.

Let's begin with the first of these claims. To understand what it implies, we need to remember that (in the sense relevant here) "cognition" (Erkenntnis) comes for Kant in both a theoretical and a practical form. ${ }^{39}$ In this sense of these terms, theoretical cognition is cognition of what is - cognition which (at least canonically) depends in some way on the existence of the object it represents.

\footnotetext{
36 See 5:119-120.

${ }_{37}$ Compare Ameriks(2003, 2011), Reath(2006, 2013), Sensen(2013), Pollok(2017).

38 But see Schafer(forthcoming-d)

${ }^{39}$ For more on my understanding of Kant's conception of cognition, see Schafer(2018-b, forthcoming-b), for other important work on this topic, see Smit(2000), Willashek and Watkins(2018), and Tolley(manuscript).
} 
Practical cognition, on the other hand, is characterized by Kant as cognition of what ought to be. 40 As such, as Kant understands it, it is a form of cognition which (canonically) relates to its object by being the ground of that object's existence. ${ }^{41}$

It is crucial to keep both of these forms of cognition in mind when reading the first of these characterizations. Otherwise, we might miss that Kant's characterization of reason as the faculty for "cognition from principles" applies equally to both theoretical and practical reason. In other words, for Kant both theoretical reason and practical reason aim at this sort of principled cognition. The only difference between them lies in the sort of "cognition from principles" they aim at - and, in particular, in the manner in which this cognition relates to its object.

So, in this broad sense of "cognition", reason for Kant is "cognitive" in both its theoretical and its practical manifestations. ${ }^{42}$ But this, of course, does not distinguish reason from our other cognitive faculties. What is distinctive of reason, on this characterization, is its concern for cognition from principles in particular. What this means is a complicated question, but the fundamental idea here is simple enough. One has cognition from principles, in the sense relevant here, just insofar as one's cognitions are grounded in even more fundamental and more general cognitions. So, for example, one has theoretical cognition from principles insofar as one's cognition of what is is grounded in cognition of other, more basic features of reality. It is the search for this sort of systematic or principled cognition that is distinctive of reason in particular for Kant, on this characterization of reason.

Given this, cognition from principles involves a grasp, not just of which properties something has (or ought to have), but also of how these ground one another. In other words, cognition from principles goes beyond mere cognition (Erkenntnis) to encompass what Kant calls comprehension (Begreifen). For comprehension in Kant's sense differs from mere cognition precisely insofar as it involves a grasp of these sorts of explanatory relations. Thus, comprehension in Kant's sense involves something like the sort of cognitive achievement which contemporary epistemologists like to call "understanding".

This brings us to the second of our characterizations of reason's function - namely, the idea of reason as the faculty for comprehension - or, to put things in more contemporary jargon, reason as the faculty for understanding. Once again, it is crucial that comprehension or understanding in this sense may be either theoretical - an understanding of what is - or practical - an understanding of what ought to be. So, on this characterization, the ultimate task of reason is to achieve a systematic understanding of both what is and what ought to be.43

Turning to the third of these characterizations of reason, one of Kant's deepest insights is that this second way of characterizing reason is ultimately equivalent to our third. There is a great to say about this connection, but again the basic idea is simple enough. In particular, on Kant's conception of autonomy, for reason to be autonomous is just for its activities to be determined only by reason's own a priori principles. So, for example, the activity of practical reason will be autonomous just in

\footnotetext{
40 See (e.g.) A633/B661.

${ }^{41}$ See (e.g.) Bix-x.

${ }^{42}$ Compare Engstrom(2009). Of course, the idea that practical reason is cognitive in this sense is not uncontroversial.

For example, contrast Neiman(1994) on this point.

43 This focus on comprehension/understanding as the ultimate cognitive aim of reason marks one important difference between my interpretation and Engstrom's.
} 
case this activity is an (absolute or unqualified) instance of practical cognition from principles. And, as just laid out, practical cognition from principles is just practical comprehension. So, to say that reason's telos lies in autonomy is equivalent to saying that it lies in comprehension.

In this way, it is not too difficult to see why Kant would regard these three characterizations of reason as equivalent to one another. And given this, Reason-First Constitutivism can be made more precise in either of the following ways:

Understanding-First Constitutivism: The most fundamental norms that apply to us are grounded in our nature as rational beings or creatures with the capacity for (theoretical and practical) understanding.

Autonomy-First Constitutivism: The most fundamental norms that apply to us are grounded in our nature as rational beings or creatures with the capacity for antonomy.

One of the strengths of the Kant's approach to constitutivism, and of the conception of reason which sits at its heart, is the manner in which it brings together these two characterizations of the core of constitutivism. This, of course, is also significant for the relationship between between Reason-First Constitutivism and Agency-First Constitutivism in their most Kantian forms. For, of course, the most Kantian forms of Agency-First Constitutivism conceive of agency precisely as the capacity for autonomy. As a result, in their most Kantian forms, Agency-First Constitutivism and Reason-First Constitutivism do indeed converge with one another - just as we suggested above. 


\section{Works Cited}

All references to Kant's works (other than the first Critique) use the standard Academy references. References to the first Critique use the standard A/B notation.

Allison, Henry E. (1990). Kant's Theory of Freedom. Cambridge: Cambridge University Press.

Ameriks, Karl. (2003) "Kant's Transcendental Deduction as a Regressive Argument," in Interpreting Kant's Critiques (Oxford: Oxford University Press).

—. (2011). Kant's Elliptical Path. Oxford: Oxford University Press.

Bagnoli, Carla. (2013) "Constructivism about Practical Knowledge.” C. Bagnoli (ed.) Constructivism in Ethics. Cambridge: Cambridge University Press.

—_. (2011) "Constructivism in Metaethics." Stanford Encyclopedia of Philosophy.

Boghossian, Paul. (2008) “Epistemic Rules,” The Journal of Philosophy, 105(9): 472-500.

—. (2014) “What is inference?” Philosophical Studies, 169(1): 1-18.

Boyle, Matthew. (2009) “Two Kinds of Self-Knowledge," Philosophy and Phenomenological Research 58:1.

Breitenbach, Angela. (2014) "Biological Purposiveness and Analogical Reflection" in I. Goy and E. Watkins (eds.) Kant's Theory of Biology. Berlin/New York: de Gruyter, 131-148.

Burge, Tyler. (2010) Origins of Objectivity. Oxford: Oxford University Press.

Cohen, Alix. (2009) Kant on the Human Sciences: Biology, Anthropology and History. London: Palgrave.

Conant, James. (1991) “The Search for Logically Alien Thought: Descartes, Kant, Frege and the Tractatus" in The Philosophy of Hilary Putnam, Philosophical Topics, 20:1, 115-180.

Engstrom, Stephen. (2002). "Kant's Distinction Between Theoretical and Practical Knowledge," The Harvard Review of Philosophy 10 (1):49-63.

- (2009) The Form of Practical Knowledge: A Study of the Categorical Imperative. Cambridge: Harvard University Press.

—. (2013) "Constructivism and Practical Knowledge." in C. Bagnoli (ed.) Constructivism in Ethics. Cambridge: Cambridge University Press.

Enoch, David. (2006) “Agency, Shmagency: Why Normativity Won't Come from What Is Constitutive of Action.” Philosophical Review 115: 169-98.

—. (2011) "Shmagency Revisited." in Michael Brady (ed.) New W aves in Metaethics. New York: Palgrave Macmillan. 
Ferrero, Luca. (2009) "Constitutivism and the Inescapability of Agency," Oxford Studies in Metaethics 4 303-333.

Foot, Philippa. (2003) Natural Goodness. Oxford: Oxford University Press.

Fugate, Cortney. (2014). The Teleology of Reason. Berlin: Walter de Gruyter.

Ginsborg, Hannah. (2015) The Normativity of Nature: Essays on Kant's Critique of Judgement. Oxford: Oxford University Press.

Grier, Michelle. (2005) Kant's Doctrine of Transcendental Illusion. Cambridge: Cambridge University Press.

Guyer, Paul. (2008) Knowledge, Reason, and Taste: Kant's Response to Hume. Princeton: Princeton University Press.

Haag, Johannes. (2014) "Faculties in Kant and German Idealism" in Perler, D. (ed.) Faculties. Oxford Philosophical Concepts. Oxford: Oxford University Press.

Herman, Barbara. (1993) The Practice of Moral Judgment. Cambridge: Harvard University Press.

—. (2007) Moral Literary. Cambridge: Harvard University Press.

Hlobil, Ulf. (forthcoming) "Inferring by Attaching Inferential Force.” Australasian Journal of Philosophy.

James, Aaron. (2012) "Constructing Protagoreon Objectivity." in J. Lenman \& Y. Shemmer (eds.), Constructivism in Practical Philosophy. Oxford: Oxford University Press.

Katsafanas, Paul. (2013) Agency and the Foundations of Ethics: Nietzschean Constitutivism. Oxford: Oxford University Press.

Kern, Andrea. (2018) Sources of Knowledge: On the Concept of a Rational Capacity for Knowledge. Cambridge: Harvard University Press.

Korsgaard, Christine. (1996) The Sources of Normativity. Cambridge: Cambridge University Press.

—. (2008) The Constitution of Agency: Essays on Practical Reason and Moral Psychology. Oxford: Oxford University Press.

—. (2009) Self-Constitution: Agency, Identity, and Integrity. Oxford: Oxford University Press.

O’Neill, Onora. (1989) Constructions of Reason. Cambridge: Cambridge University Press.

Lavin, Doug. (forthcoming) "Pluralism about Agency."

Lindeman, Kathryn. (2017) "Constitutivism without Normative Thresholds," Journal of Ethics and Social Philosophy 12:3. 
Longuenesse, Beatrice. (1998) Kant and the Capacity to Judge. Sensibility and Discursivity in the

Transcendental Analytic of the Critique of Pure Reason, Princeton: Princeton University Press.

—. (2017) I, Me, Mine. Back to Kant, and Back Again, Oxford University Press.

Lord, Errol and Sylvan, Kurt. (forthcoming) "Reasons: Wrong, Right, Normative, Fundamental," Journal of Ethics and Social Philosophy.

MacFarlane, John. (2002) "Frege, Kant, and the Logic in Logicism", The Philosophical Review 111, 2565.

Marshall, Colin (forthcoming) "Kant's derivation of the moral 'ought' from a metaphysical 'is'." in N. Stang and K. Schafer (eds.). Sensible and Intelligible Worlds, Oxford; Oxford University Press.

McDowell, John. (2006) “The Disjunctive Conception of Experience as Material for a Transcendental Argument," Teorema, 25: 19-33.

Mudd, Sasha. (2017). "The demand for systematicity and the authority of theoretical reason in Kant.” Kantian Review 22(1), 81-106.

Neiman, Susan. (1994) The Unity of Reason: Rereading Kant. Oxford: Oxford University Press.

Neta, Ram. (forthcoming) “The Basing Relation," The Philosophical Review.

Nunez, Tyke. (2018) “Logical Mistakes, Logical Aliens, and the Laws of Kant's Pure General Logic," Mind.

Paakkunainen, Hille. (2018) "Doing Away with the Shmagency Objection: How Constitutivism Works in Principle," Manuscrito.

Pollok, Konstantin. (2017) Kant's Theory of Normativity. Cambridge: Cambridge University Press.

Reath, Andrews. (2006) Agency and Autonomy in Kant's Moral Theory. Oxford: Oxford University Press.

_- (2013) "Formal Approaches to Kant's Formula of Humanity" in S. Baiasu and M. Timmons, (eds.) Kant on Practical Justification: Interpretive Essays. Oxford: Oxford University Press, 201-228.

Rödl, Sebastian. (2018) Self-Consciousness and Objectivity. An Introduction to Absolute Idealism. Cambridge: Harvard University Press.

Schafer, Karl. (forthcoming-a) "Rationality: The Capacity for Understanding." Noûs.

-. (forthcoming-b ) "Kant's Conception of Cognition and Our Knowledge of Things in Themselves," in K. Schafer and N. Stang (eds.) The Sensible and Intelligible Worlds, Oxford: Oxford University Press.

—. (forthcoming-c) "A Kantian Virtue Epistemology." Synthese. 
—. (forthcoming-d) Reason's Unity: The Nature of Reason and its Place in Kant's Critical System.

- (2018-a) "Constitutivism about Reasons: Autonomy and Understanding," in K. Jones and F. Schroeter (eds.) The Many Moral Rationalisms, Oxford: Oxford University Press.

- (2018-b) "Practical Cognition and Knowledge of Things-in-Themselves," in D. Heide and E. Tiffany (eds.) Kantian Freedom, Oxford: Oxford University Press.

—. (2017) “Objects and Intuitions in Manifest Reality,” Philosophical Studies 174:7: 1675-1686.

—. (2015-a) "Realism and Constructivism in Kantian Metaethics 1," Philosophy Compass.

- (2015-b) "Realism and Constructivism in Kantian Metaethics 2," Philosophy Compass.

—_. (2013) "Perception and the Rational Force of Desire," Journal of Philosophy 110:5: 258-281.

Schönecker, Dieter. (2006). "How is a Categorical Imperative Possible?" in Groundwork for the Metaphysics of Morals, eds. Christoph Horn and Dieter Schönecker. Berlin: De Gruyter. 40

Sensen, Oliver. (2013 "Kant's Constructisivm" in C. Bagnoli (ed.) Constructivism in Ethics, Cambridge: Cambridge University Press, 63-81.

Setiya, Kieran. (2013)Knowing Right from Wrong. Oxford: Oxford University Press.

Silverstein, Matthew. (2015) “The Shmagency Question.” Philosophical Studies 172:5, 1127-42.

Smit, Houston. (2000) "Kant on Marks and the Immediacy of Intuition." The Philosophical Review 109: 235-66.

Smith, Michael. (2012) "Agents and Patients, or: What We Learn About Reasons for Action by Reflecting on Our Choices in Process-of-Thought Cases." Proceedings of the Aristotelian Society 112.3: 309-331.

- (2013) "A Constitutivist Theory of Reasons: Its Promise and Parts." LEAP: Law, Ethics, and Philosophy 1:9-30.

Street, Sharon. (2008) "Constructivism about Reasons." Oxford Studies in Metaethics, 3. Ed. Russ Shafer-Landau. Oxford: Clarendon Press.

Thompson, Michael. (2008) Life and Action: Elementary Structures of Practice and Practical Thought. Cambridge: Harvard University Press.

Thomson, J.J. (2008) Normativity. New York: Open Court.

Tiffany, Evan. (2012) "Why Be an Agent?" Australasia Journal of Philosophy 90.2, 1-11. 
Tolley, Clinton. (manuscript) Kant's Doctrine of Appearances: Transcendental Idealism as a Theory of Intentionality.

Velleman, David. (2000) The Possibility of Practical Reason. Oxford: Clarendon Press.

—. (2009) How We Get Along. Cambridge: Cambridge University Press.

Walden, Kenny. (2012) "Laws of Nature, Laws of Freedom, and the Social Construction of Normativity." Oxford Studies in Metaethics, 7.

—. (forthcoming) "Reason and Respect," Oxford Studies in Metaethics.

Watkins, Eric. (2018) Kant on Laws. Cambridge: Cambridge University Press.

Willashek, Markus. (forthcoming) Necessary Questions. Cambridge: Cambridge University Press.

Willashek, Markus and Watkins, Eric. (2018) “Kant on Cognition.” Journal of the History of Philosophy.

Wood, Allen. (1999) Kant's Ethical Thought. Cambridge: Cambridge University Press. 